\title{
Collision, Adhesion, and Oxidation of Single Ag Nanoparticles on a Polysulfide-Modified Microelectrode
}

\author{
Peter A. Defnet and Bo Zhang* \\ Department of Chemistry, University of Washington, Seattle Washington United States 98195-1700
}

Corresponding author, zhangb@uw.edu

Table of Contents:

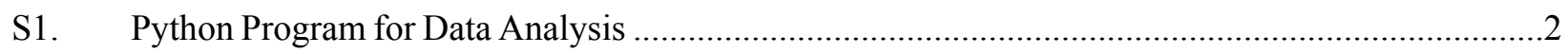

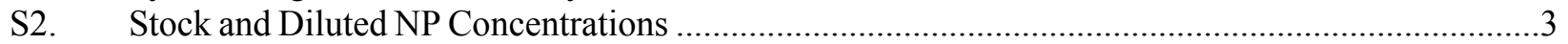

S3. Optimization of Alkaline Thiosulfate NP Collision Condition .....................................................

S4. Cyclic Voltammetry in Alkaline Thiosulfate .........................................................................

S5. $\quad$ NP Volume Estimation using 2D Projection Method with TEM Data ........................................

S6. $\quad$ Representative TEM Images for Ag NPs ........................................................................ 9

S7. Representative NP Collision Traces for 30, 40, 60, 80, $100 \mathrm{~nm}$ Ag NPs ....................................10

S8. Representative NP Collision Events for $10 \mathrm{mM} \mathrm{Na}_{2} \mathrm{~S}_{2} \mathrm{O}_{3} 10 \mathrm{mM} \mathrm{NaOH}$ with Polysulfide .............11

S9. Representative NP Collision Events for $10 \mathrm{mM} \mathrm{Na}_{2} \mathrm{~S}_{2} \mathrm{O}_{3} 10 \mathrm{mM} \mathrm{NaOH}$ without Polysulfide ........12

S10. Representative NP Collision Events for $10 \mathrm{mM} \mathrm{KCl} 10 \mathrm{mM} \mathrm{NaOH}$....................................... 13

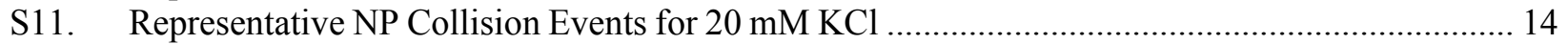

S12. Equilibrium Describing the Improved Solubility of Ag-Salts from a Lewis Base........................ 15

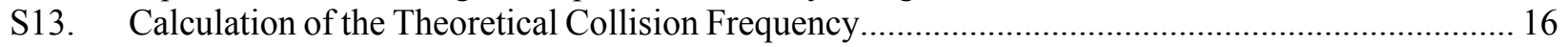

S14. Investigation of Au-Oxide Formation During the Polysulfide Passivation Process...................... 17

S15. Measurement of the Electroactive Surface Area of Bare and Polysulfide-Removed Au Electrodes 


\section{S1. Python Program for Data Analysis}

The accurate quantitation of integrated charge to calculate the equivalent spherical diameter for each Ag NP collision peak is dependent on selecting an accurate baseline. Methods utilizing manual baseline selection risk introducing systematic errors or selection bias towards anticipated results. We instead designed a custom Python script that programmatically adjusts the baseline to zero and extracts peak parameters including amplitude, duration, and area under the curve (integrated charge).

The script assumes a flat, elevated baseline containing positive-going peaks. We first used $3^{\text {rd }}$ order polynomial curve-fitting to adjust the baseline to approximately zero on 30 -second sections of the trace. The index of each peak max were then identified, and more rigorous baseline adjustment was performed with linear curve-fitting. Here, 500 points $10 \mathrm{~ms}$ before the peak were averaged, and separately 500 points $50 \mathrm{~ms}$ after the peak were averaged (where each point is recorded every $10 \mu \mathrm{s}$ ). The resulting 2 averages were linearly fit and adjusted to zero, thus ensuring a precisely zero baseline. Results were then checked by manual inspection and clear examples of non-zero baselines were rejected. All peaks with heights exceeding $3 x$ the peak-to-peak noise of the trace were quantified. 


\section{S2. Stock and Diluted NP Concentrations}

All NP collision experiments were prepared by adding $300 \mu \mathrm{L}$ of stock Ag NPs to the $5 \mathrm{~mL}$ total volume. We provide each stock and diluted Ag NP concentration in the table below. The stock NP concentration (Particles/mL) was obtained from the manufacturer (Nanocomposix, San Diego, CA) in the characterization data of the purchased samples.

The stock NP concentration (Particles/mL) was converted to pM with using Equation S1, where $N_{A}$ is Avogadro's Number $\left(6.022 \times 10^{23}\right)$.

$$
\text { Stock }\left(\frac{\text { Particles }}{m L}\right) * \frac{1000\left(\frac{m L}{L}\right)}{N_{A}\left(\frac{\text { Particles }}{m o l}\right)} * 10^{12}=\operatorname{Stock}(p M)
$$

The diluted NP concentration (pM) was calculated with Equation S2.

$$
\text { Stock }(p M) * \frac{0.3 m L}{5 m L}=\text { Diluted }(p M)
$$

\begin{tabular}{|c|c|c|c|}
\hline NP Diameter $(\mathrm{nm})$ & $\begin{array}{c}\text { Stock NP Concentration } \\
(\text { Particles/mL) }\end{array}$ & $\begin{array}{c}\text { Stock NP Concentration } \\
(\mathrm{pM})\end{array}$ & $\begin{array}{c}\text { Diluted NP Concentration } \\
(\mathrm{pM})\end{array}$ \\
\hline 30 & $1.60 \times 10^{11}$ & 2656.9 & 159.4 \\
\hline 40 & $5.70 \times 10^{10}$ & 946.5 & 56.8 \\
\hline 60 & $1.90 \times 10^{10}$ & 315.5 & 18.9 \\
\hline 80 & $1.10 \times 10^{10}$ & 126.2 & 7.6 \\
\hline 100 & $7.60 \times 10^{09}$ & 71.4 & 4.3 \\
\hline
\end{tabular}




\section{S3. Optimization of Alkaline Thiosulfate NP Collision Condition}

The polysulfide-modified thiosulfate condition used in the main text contained $10 \mathrm{mM} \mathrm{Na} 2 \mathrm{~S}_{2} \mathrm{O}_{3}$ $10 \mathrm{mM} \mathrm{NaOH}$ in the bulk solution. We selected this condition by systematically varying both the $\mathrm{Na}_{2} \mathrm{~S}_{2} \mathrm{O}_{3}$ and $\mathrm{NaOH}$ concentrations. Representative traces and respective data analyses are shown below.

The use of less than $10 \mathrm{mM} \mathrm{Na}_{2} \mathrm{~S}_{2} \mathrm{O}_{3}$ consistently delayed the onset of collision events by over 5 minutes. See the $6 \mathrm{mM} \mathrm{Na}_{2} \mathrm{~S}_{2} \mathrm{O}_{3} 10 \mathrm{mM} \mathrm{NaOH}$ trace below as a representative example. This effect was repeatably observed for $5 \mathrm{mM}, 6 \mathrm{mM}$, or $7 \mathrm{mM} \mathrm{Na} \mathrm{S}_{2} \mathrm{O}_{3}$ with $10 \mathrm{mM} \mathrm{NaOH}$. However, use of more than $10 \mathrm{mM} \mathrm{Na}_{2} \mathrm{~S}_{2} \mathrm{O}_{3}$ significantly increased the rate of aggregation, obscuring the single particle collision results. See the rapid decrease in collision frequency in the $15 \mathrm{mM} \mathrm{Na}_{2} \mathrm{~S}_{2} \mathrm{O}_{3} 10 \mathrm{mM} \mathrm{NaOH}$ trace and broadening of the calculated diameter distribution for evidence.

We wanted to keep the $\mathrm{pH}$ of the solution above the $\mathrm{pKa}$ of thiosulfate (11.35) to promote better complexation with $\mathrm{Ag}^{+}$. However, increasing the $\mathrm{NaOH}$ concentration above $10 \mathrm{mM}$ led to noticeable aggregation, evidenced in decrease in collision frequency in the $10 \mathrm{mM} \mathrm{Na}_{2} \mathrm{~S}_{2} \mathrm{O}_{3} 20 \mathrm{mM} \mathrm{NaOH}$ trace, and broadening of the calculated diameter distribution below. Thus, the selected $10 \mathrm{mM} \mathrm{Na}_{2} \mathrm{~S}_{2} \mathrm{O}_{3} 10 \mathrm{mM}$ $\mathrm{NaOH}$ provided the best tradeoff by maintaining the appropriate $\mathrm{pH}$ and avoiding significant aggregation within a 30-minute recording period.

All traces below were recorded using 19 pM $60 \mathrm{~nm} \mathrm{Ag} \mathrm{NP's,} \mathrm{and} \mathrm{with} \mathrm{the} \mathrm{polysulfide-}$ pretreatment pulse methodology prepared in their respective solutions. For the distributions, $n=654$, 1943, and 337, for the $6 \mathrm{mM}, 10 \mathrm{mM}, 15 \mathrm{mM} \mathrm{Na}_{2} \mathrm{~S}_{2} \mathrm{O}_{3}$ in $10 \mathrm{mM} \mathrm{NaOH}$, and $\mathrm{n}=413$ for the $10 \mathrm{mM}$ $\mathrm{Na}_{2} \mathrm{~S}_{2} \mathrm{O}_{3} 20 \mathrm{mM} \mathrm{NaOH}$. We chose to plot the KDE instead of a gaussian fit to better show the broadened distribution shapes.

For the traces shown below we further acknowledge that increasing the $\mathrm{Na}_{2} \mathrm{~S}_{2} \mathrm{O}_{3}$ concentration evidently increases the amplitude of the measured peak. It has been previously reported by Krause et al. that peaks recorded in low electrolyte concentration $(<20 \mathrm{mM})$ are limited by the diffusion of electrolyte to the particle. ${ }^{1}$ Thus, with a higher concentration of electrolyte present, generated $\mathrm{Ag}^{+}$can be stabilized faster and generate a higher amplitude.

\section{References in S3:}

(1) Krause, K. J.; Brings, F.; Schnitker, J.; Katelhon, E.; Rinklin, P.; Mayer, D.; Compton, R. G.; Lemay, S. G.; Offenhausser, A.; Wolfrum, B. The Influence of Supporting Ions on the Electrochemical Detection of Individual Silver Nanoparticles: Understanding the Shape and Frequency of Current Transients in Nano-Impacts. Chem. Eur. J. 2017, 23, 4638-4643. 

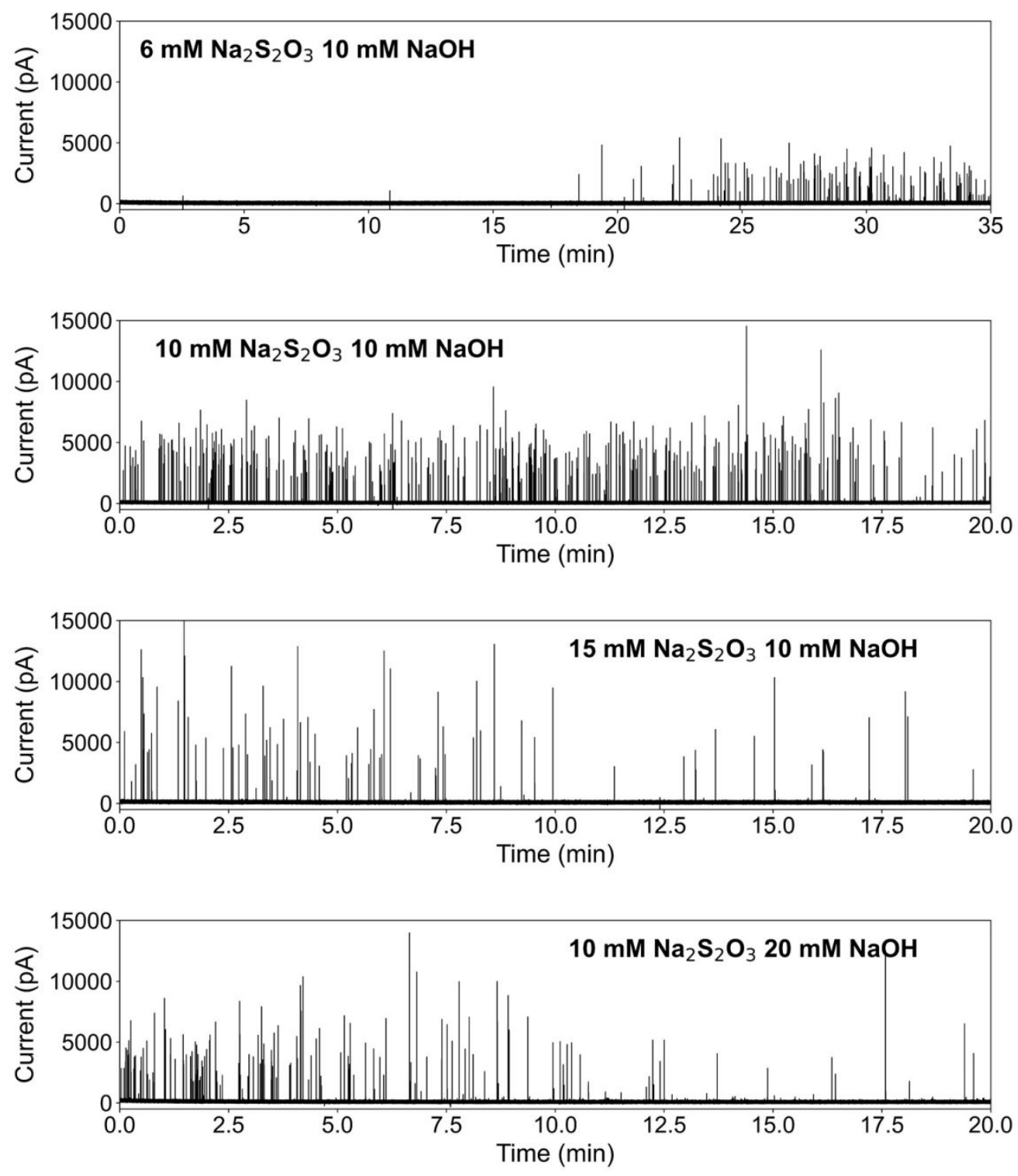

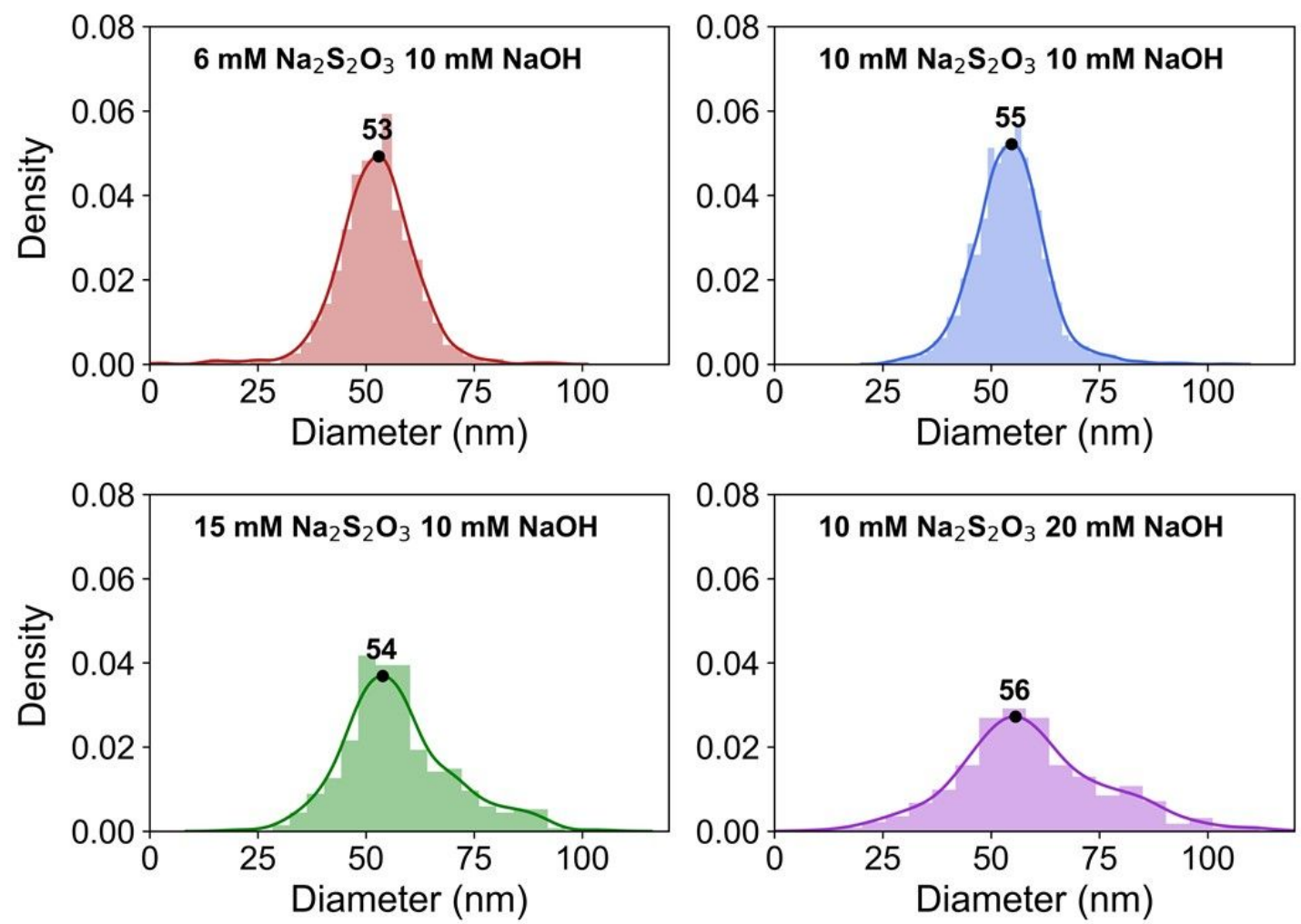


\section{S4. Cyclic Voltammetry in Alkaline Thiosulfate}

(A.) A cyclic voltammogram sweeping from $-0.2 \mathrm{~V}$ to $0.6 \mathrm{~V}$ to $-0.2 \mathrm{~V}$ whereby thiosulfate oxidation occurs at $\sim 0.35 \mathrm{~V}$ followed by electrode passivation. Reduction of the film occurs at $-0.2 \mathrm{~V}$, which promotes identical voltammetry dynamics on the subsequent cycles. (B.) If the CV is instead only scanned to a minimum of $0 \mathrm{~V}$, then the large thiosulfate oxidation wave becomes smaller on each successive scan, indicative of electrode passivation.

A.

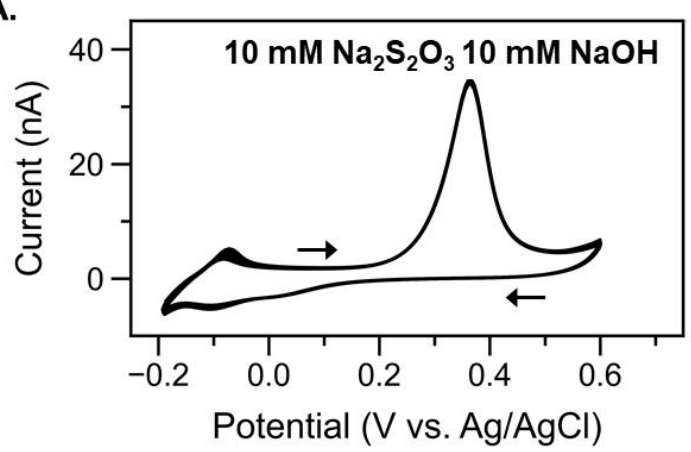

B.

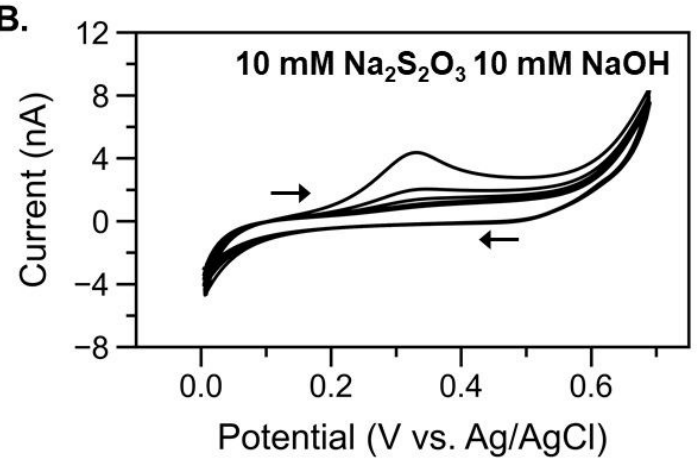




\section{S5. NP Volume Estimation using 2D Projection Method with TEM Data}

Here we show the process of using the 2D projection method to analyze TEM data for an $80 \mathrm{~nm}$ Ag NP sample. The original image (A) is thresholded using ImageJ in (B), and the area of each object is calculated in (C). The measured area is used to calculate the radius of the equivalent sphere.

A.

\begin{tabular}{|c|c|c|c|}
\hline NP \# & Measured Area $\left(\mathrm{nm}^{2}\right)$ & $\begin{array}{c}\text { Equivalent Spherical } \\
\text { Radius }(\mathrm{nm})\end{array}$ & $\begin{array}{c}\text { Equivalent Diameter } \\
(\mathrm{nm})\end{array}$ \\
\hline 1 & 4043 & 35.9 & 71.8 \\
\hline 2 & 3836 & 35.1 & 70.2 \\
\hline 3 & 5538 & 42 & 84.0 \\
\hline
\end{tabular}

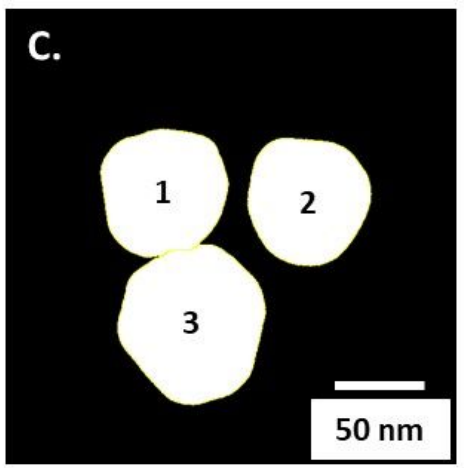

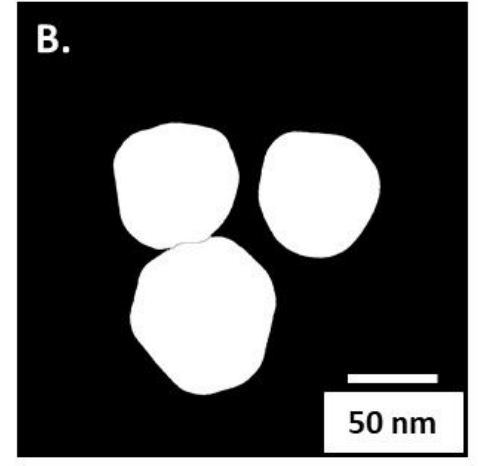

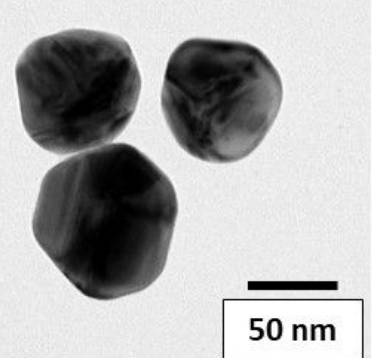

er




\section{S6. Representative TEM Images for Ag NPs}

Images are provided for 30, 40, 60, 80, and $100 \mathrm{~nm} \mathrm{Ag} \mathrm{NP's} \mathrm{for} \mathrm{A-E,} \mathrm{respectively.} \mathrm{Images} \mathrm{were}$ sized with equivalent scale bars to better illustrate quasi-sphericity of larger NPs.
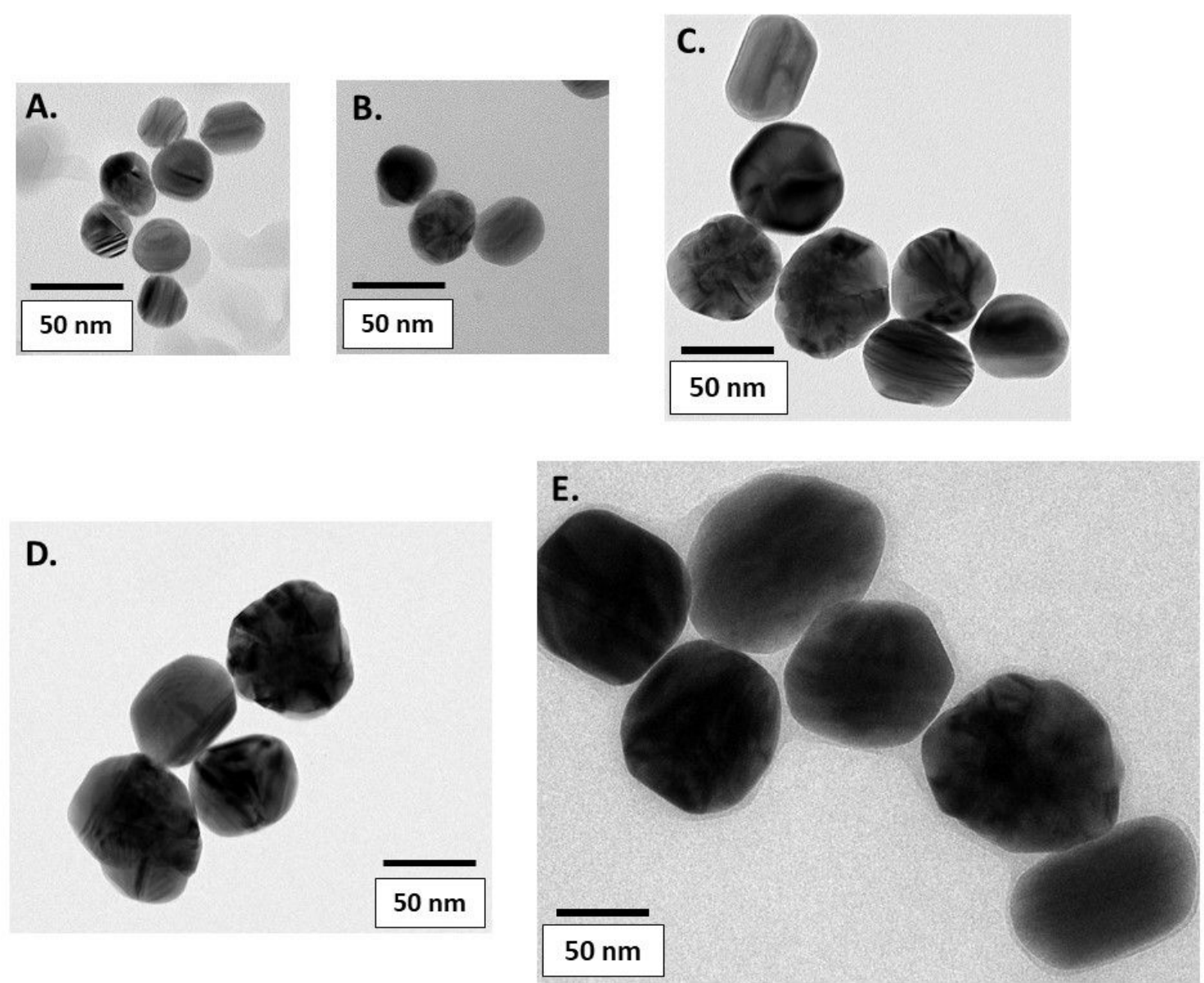


\section{S7. Representative NP Collision Traces for 30, 40, 60, 80, $100 \mathrm{~nm}$ Ag NPs}

Traces were recorded using the polysulfide-modified Au electrode in $10 \mathrm{mM} \mathrm{Na}_{2} \mathrm{~S}_{2} \mathrm{O}_{3} 10 \mathrm{mM}$ $\mathrm{NaOH}$ with the same diluted NP concentrations as displayed in $\mathbf{S 2}$. The equivalent diameter distributions are summarized in Figure 5.
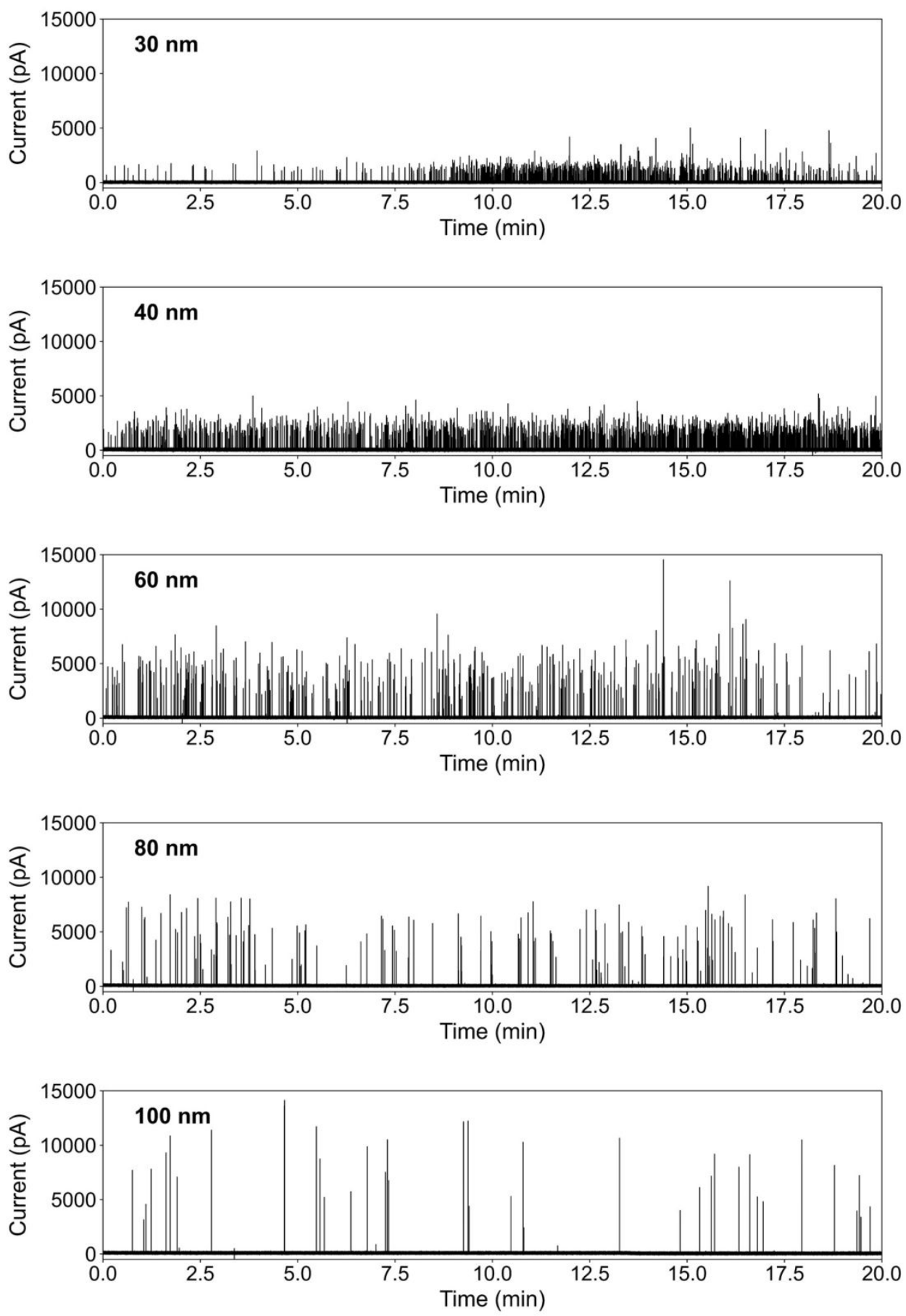


\section{S8. Representative NP Collision Events for $10 \mathrm{mM} \mathrm{Na}_{2} \mathrm{~S}_{2} \mathrm{O}_{3} 10 \mathrm{mM} \mathrm{NaOH}$ with Polysulfide}

Note that the y-axis scaling is 2 times that of the axes shown in Figures S9-11.
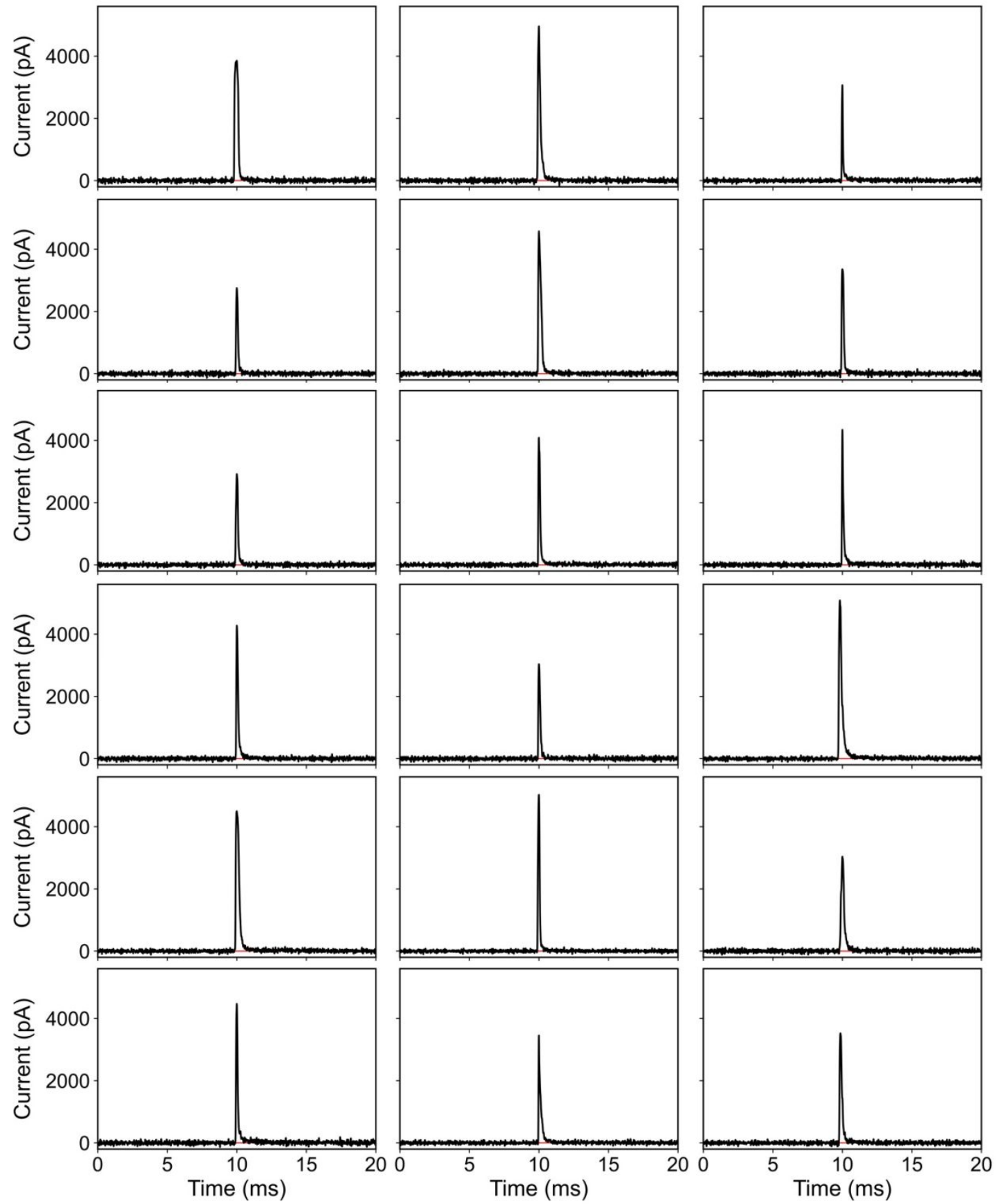
S9. Representative NP Collision Events for $10 \mathrm{mM} \mathrm{Na}_{2} \mathrm{~S}_{2} \mathrm{O}_{3} 10 \mathrm{mM} \mathrm{NaOH}$ without Polysulfide
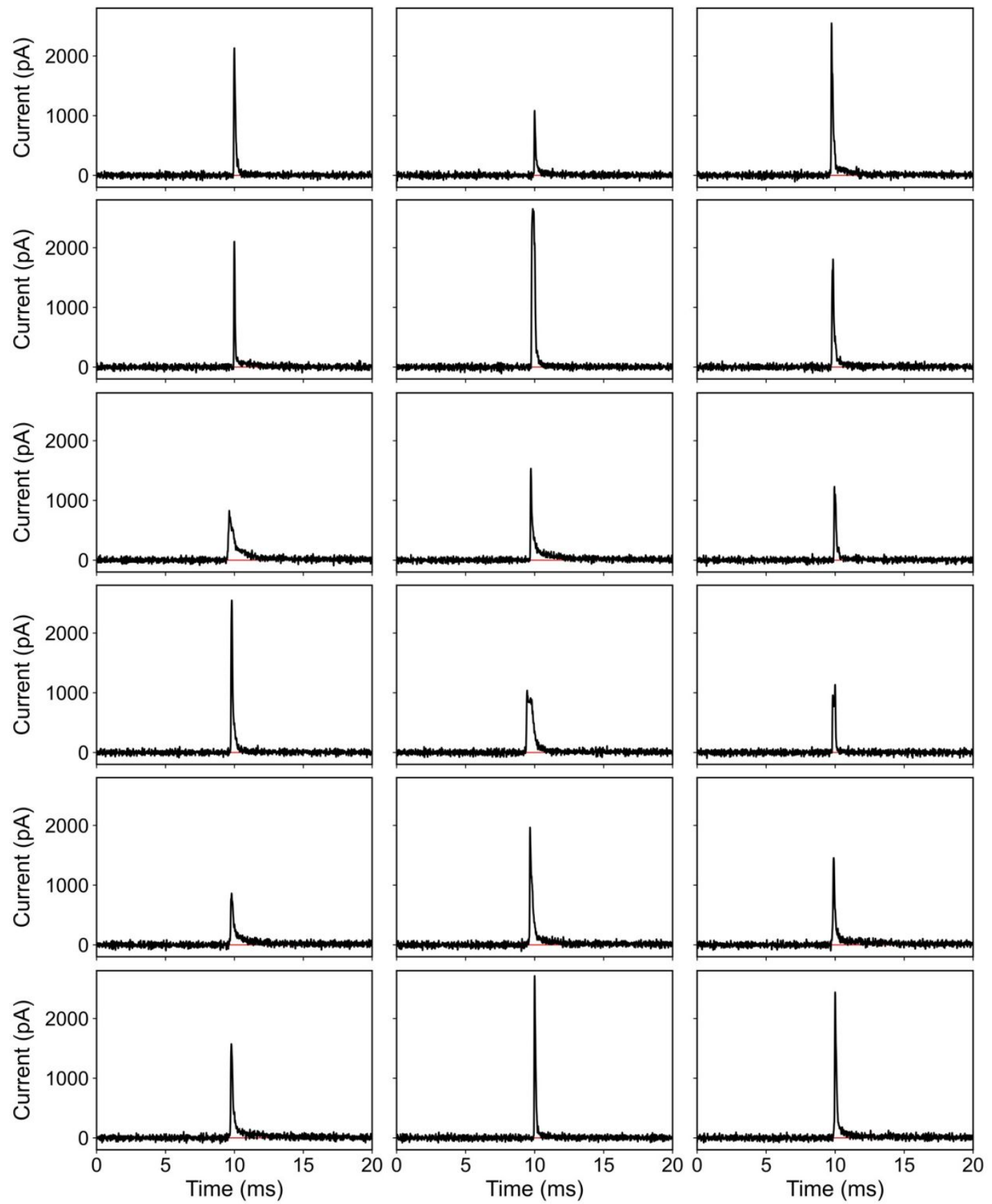
S10. Representative NP Collision Events for $10 \mathrm{mM} \mathrm{KCl} 10 \mathrm{mM}$ NaOH
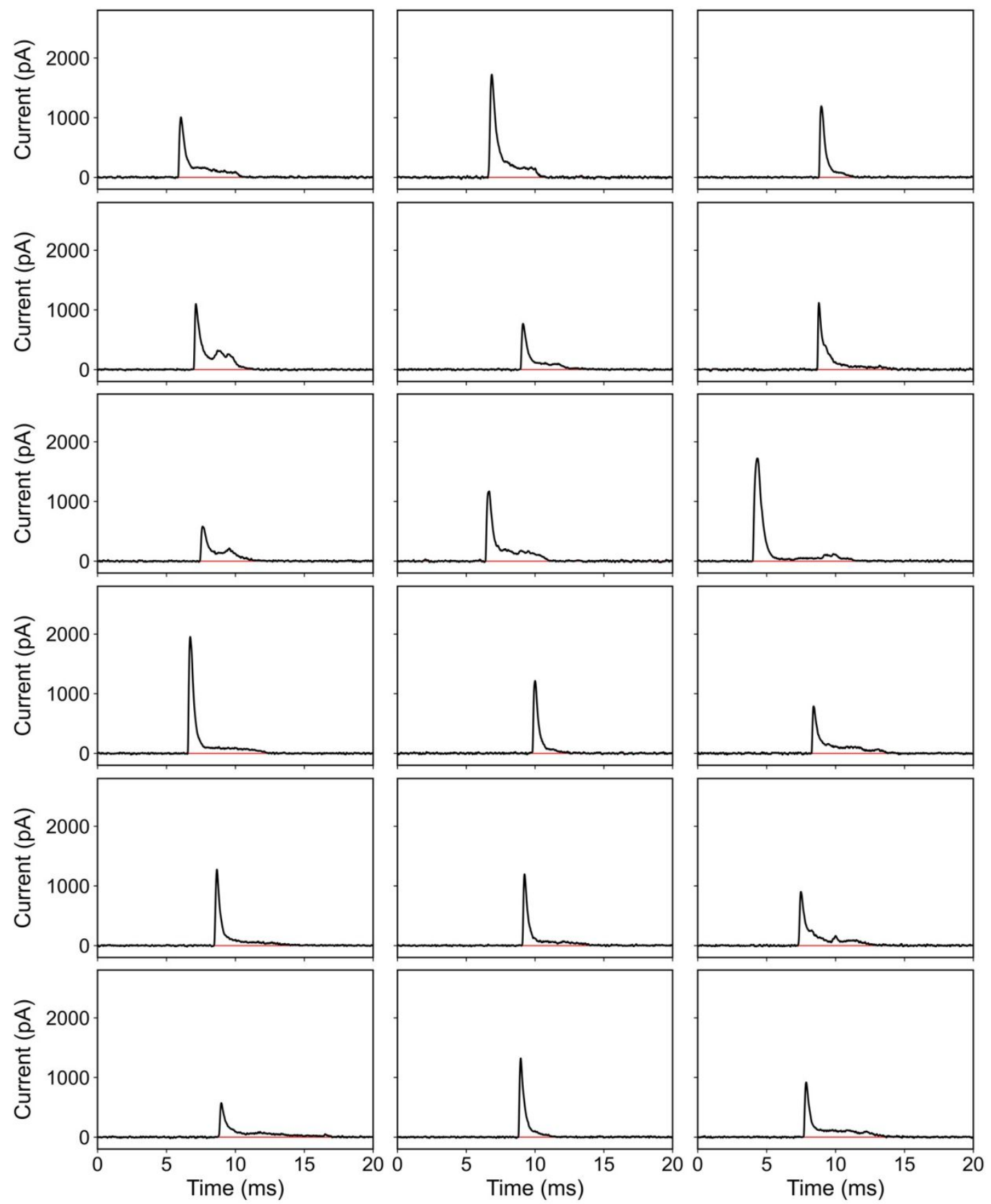
S11. Representative NP Collision Events for $20 \mathrm{mM} \mathrm{KCl}$
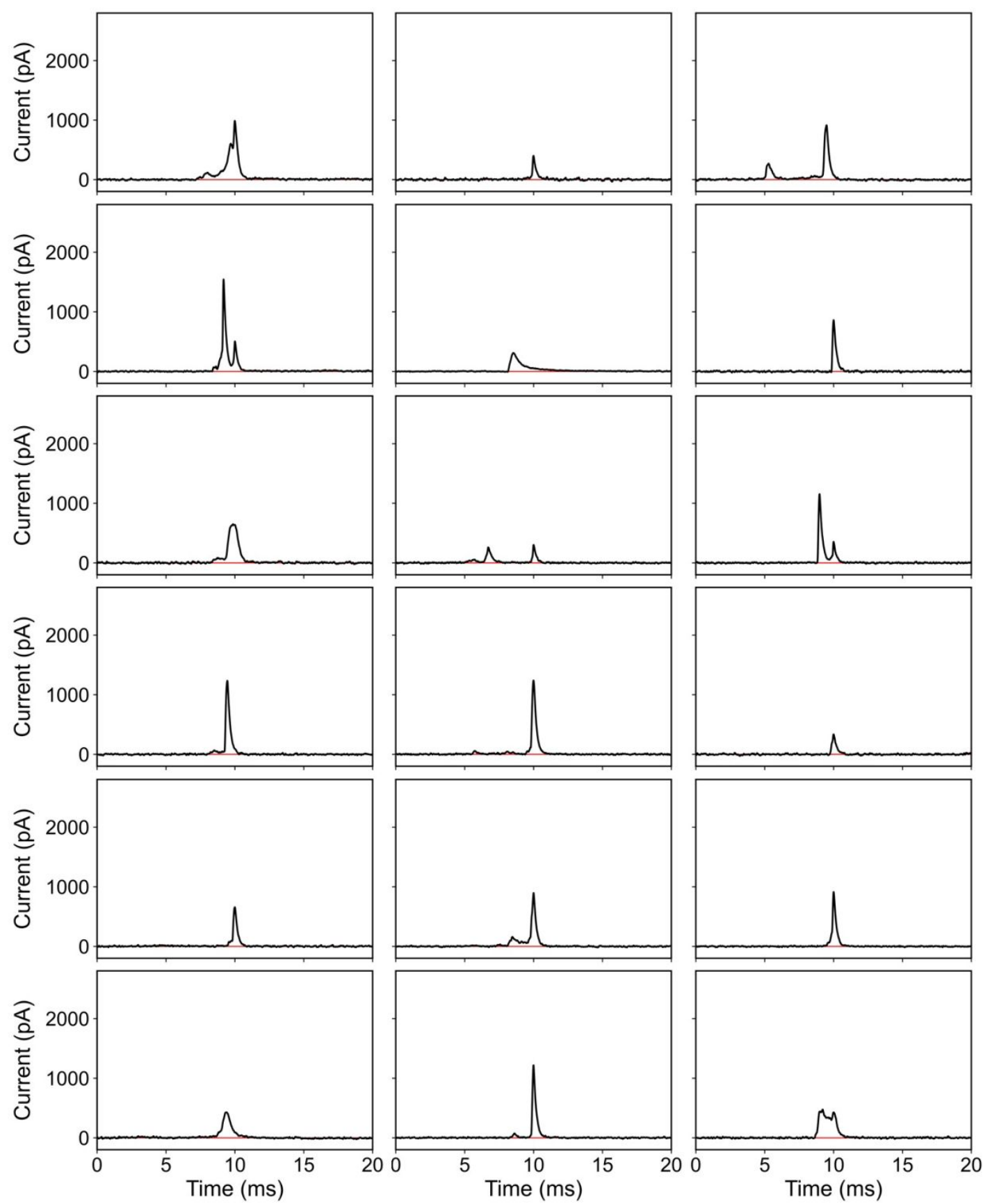


\section{S12. Equilibrium Describing the Improved Solubility of Ag-Salts from a Lewis Base}

The solubility of a compound in the absence of a Lewis base is described by its $\mathrm{K}_{\mathrm{sp}}$. For example, the equilibrium describing the dissolution of $\mathrm{Ag}_{2} \mathrm{~S}$ in water is shown below. The small value of the $\mathrm{K}_{\mathrm{sp}}$ suggests that $\mathrm{Ag}_{2} \mathrm{~S}$ is very insoluble in water.

$$
\mathrm{Ag}_{2} \mathrm{~S} \rightleftharpoons 2 \mathrm{Ag}^{+}+\mathrm{S}^{-} \quad \mathrm{K}_{\mathrm{sp}}=10^{-53.5}
$$

The solubility of the silver salt can be increased by introduction to a Lewis base. Here, $\mathrm{Ag}^{+}$reacts with the thiosulfate to form a complex ion. The equilibrium constant describing the complex ion formation is known as $\mathrm{K}_{\mathrm{f}}$ and is also referred to as the "formation constant". The example of $\mathrm{Ag}^{+}$reacting with thiosulfate is shown below.

$$
\mathrm{Ag}^{+}+2 \mathrm{~S}_{2} \mathrm{O}_{3}{ }^{2-} \rightleftharpoons\left[\mathrm{Ag}\left(\mathrm{S}_{2} \mathrm{O}_{3}\right)_{2}\right]^{3-} \quad \mathrm{K}_{\mathrm{f}}=1.7 \times 10^{13}
$$

The addition of both equilibrium equations describes the overall chemical process, whereby the product of $\mathrm{K}_{\mathrm{sp}}$ and $\mathrm{K}_{\mathrm{f}}$ describe the equilibrium constant for both reactions together $(\mathrm{K})$. Thus, the presence of thiosulfate increases the solubility silver salts by a factor equivalent to its formation constant, $\mathrm{K}_{\mathrm{f}}$.

$$
\mathrm{Ag}_{2} \mathrm{~S}+2 \mathrm{~S}_{2} \mathrm{O}_{3}{ }^{2-} \rightleftharpoons\left[\mathrm{Ag}\left(\mathrm{S}_{2} \mathrm{O}_{3}\right)_{2}\right]^{3-}+\mathrm{Ag}^{+}+\mathrm{S}^{-} \quad \mathrm{K}=\mathrm{K}_{\mathrm{sp}} * \mathrm{~K}_{\mathrm{f}}
$$

The presence of the Lewis base increases the solubility of all silver salts present in solution. Therefore, if any Ag-salts (such as Ag-oxide) preexist on the Ag NP surface when received from the manufacturer, the bulk thiosulfate will dissolve them before collision occurs. Although there is not convincing evidence that such salts exist, this may further increase the difference between TEM and NP collision volumetric measurements. 


\section{S13. Calculation of the Theoretical Collision Frequency}

Herein we provide a calculation of the theoretical NP collision frequency for $60 \mathrm{~nm} \mathrm{Ag} \mathrm{NPs.} \mathrm{We}$ first calculate the diffusion coefficient of a $60 \mathrm{~nm}$ Ag NP using Equation S3, shown below. Here, $D$ is the diffusion coefficient of the NP, $k_{B}$ is Boltzmann's constant $\left(1.38 \times 10^{-23} \mathrm{~J} / \mathrm{K}, T\right.$ is room temperature (293 $\mathrm{K}), \eta$ is the solvent viscosity $\left(1 \mathrm{~kg} / \mathrm{m}^{3}\right)$, and $R$ is the radius of the NP $(30 \mathrm{~nm})$.

$$
D=\frac{k_{B} T}{6 \pi \eta R}
$$

With given parameters, we calculate a diffusion coefficient of $7.26 \times 10^{-8} \mathrm{~cm}^{2} / \mathrm{s}$ for a $60 \mathrm{~nm} \mathrm{Ag}$ NP. We next utilize Equation S4, shown below, to calculate the theoretical NP collision frequency, $f$. Here, $D$ is the diffusion coefficient of the NP $\left(7.26 \times 10^{-8} \mathrm{~cm}^{2} / \mathrm{s}\right), C$ is the concentration of NPs $(18.9 \mathrm{pM})$, $r$ is the radius of the electrode $(12.5 \mu \mathrm{m})$, and $N_{A}$ is Avogadro's number $\left(6.022 \times 10^{-23}\right)$.

$$
f=4 D \operatorname{CrN}_{A}
$$

We calculate the theoretical NP collision frequency to be $4.07 \mathrm{~Hz}$. Given that our measured collision frequency with the $10 \mathrm{mM} \mathrm{Na}_{2} \mathrm{~S}_{2} \mathrm{O}_{3} 10 \mathrm{mM} \mathrm{NaOH}$ condition was $0.306 \mathrm{~Hz}$, we report a $13 \mathrm{x}$ underperformance from the theoretical landing rate. 


\section{S14. Investigation of Au-Oxide Formation During the Polysulfide Passivation Process}

Here we aim to estimate the contribution of Au oxidation in the polysulfide passivation $\mathrm{CV}$ shown in Figure 1A. We reprint the CV shown in Figure 1A below, recorded in $10 \mathrm{mM} \mathrm{Na} 2 \mathrm{~S}_{2} \mathrm{O}_{3} 10 \mathrm{mM}$ $\mathrm{NaOH}$. The large wave at $0.36 \mathrm{~V}$ is due to the oxidation of thiosulfate across the Au electrode, followed by passivation with polysulfide.

We next plot the results for a second $\mathrm{CV}$ recorded in $10 \mathrm{mM} \mathrm{KCl} 10 \mathrm{mM} \mathrm{NaOH}$, in the absence of thiosulfate. The $\mathrm{KCl}$ is included to maintain the same electrolyte concentration, however without contributing to an oxidative process on Au. Any positive-going oxidation wave is due to Au oxidation.

By comparing the two CV's it becomes clear that contributions of Au-oxidation in Figure 1A are minimal, due to the relatively small overlapping oxidation wave in the $10 \mathrm{mM} \mathrm{KCl} 10 \mathrm{mM} \mathrm{NaOH}$ condition.
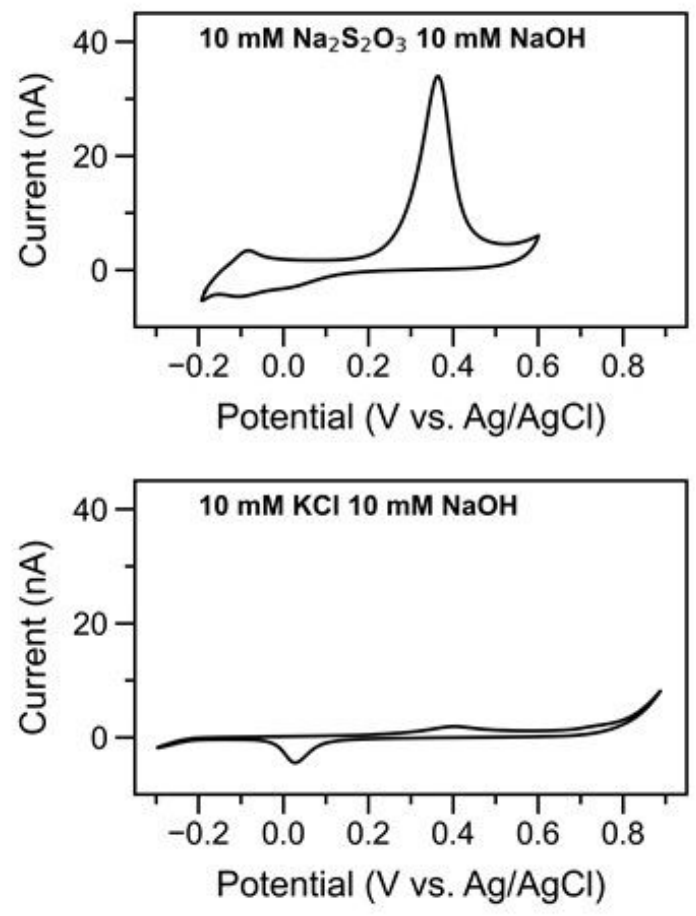


\section{S15. Measurement of the Electroactive Surface Area of Bare and Polysulfide-Removed Au Electrodes}

Here we aim to investigate whether the polysulfide modification process increases the surface area of the underlying Au electrode. If so, the increased area may account for the measured increase in NP collision frequency.

We employed the use of cyclic voltammetry in $\mathrm{H}_{2} \mathrm{SO}_{4}$ to measure the electroactive surface area (EASA) of $\mathrm{Au}$. We first measured the EASA of the bare Au electrode prior to modification. The electrode was then modified with polysulfide utilizing the potential pulse method described in the main text, and the polysulfide was subsequently removed by dissolution in toluene. The EASA of the post-modified, polysulfide-removed electrode was then measured for comparison.

The surface area of the polysulfide itself cannot be measured electrochemically given that it is a poor conductor. We instead assume a uniform polysulfide thickness given that the modification process is self-limiting. Therefore, any observed roughness will be caused by the roughening of the underlying Au electrode, likely during the Au leaching process as part of the 30 -second $0 \mathrm{~V}$ potential pulse.

Below we include a table summarizing the EASA for the Au electrode before polysulfidemodification, and after polysulfide removal with toluene for three independent trials.

\begin{tabular}{|c|c|c|}
\hline $\begin{array}{c}\text { Bare } \mathrm{Au} \\
\text { EASA }\left(\mu \mathrm{m}^{2}\right)\end{array}$ & $\begin{array}{c}\text { Post Modification and Toluene } \\
\text { Dissolution EASA }\left(\mu \mathrm{m}^{2}\right)\end{array}$ & \% Difference \\
\hline 1886.6 & 1921.7 & 1.8 \\
\hline 1897.9 & 1919.9 & 1.1 \\
\hline 1949.5 & 2015.9 & 3.3 \\
\hline
\end{tabular}

The EASA was calculated by integrating the charge of the Au-oxide reduction wave and converting to surface area with $390 \mu \mathrm{C} / \mathrm{cm}^{2}{ }^{2}$

Since the $\%$ difference values are small $(<5 \%)$, we conclude that the suspected increase in electroactive surface area is not a significant factor toward the increase in collision frequency.

\section{References in S15:}

(2) Barlow, S. T.; Louie, M.; Hao, R.; Defnet, P. A.; Zhang, B. Electrodeposited Gold on CarbonFiber Microelectrodes for Enhancing Amperometric Detection of Dopamine Release from Pheochromocytoma Cells. Anal. Chem. 2018, 90 (16). 